\title{
A trajetória de uma vida marcada pelo preconceito e exclusão social em decorrência do estigma da hanseníase: relato de experiência
}

\author{
The route of a prejudice and social exclusion life marked by due to leprosy stigma: an \\ experience report
}

\begin{abstract}
La trayectoria de una vida marcada por el prejuicio y la exclusión social como consecuencia del estigma de la enfermedad de Hansen: relato de experiencia
\end{abstract}

Marinelva Monteiro Dantas ${ }^{1 *}$, Yara da Silva dos Reis ${ }^{1}$, Jéssica Karoline Alves Portugal ${ }^{1}$, Marcelo Henrique da Silva Reis ${ }^{1}$, Jaynne de Souza Dantas ${ }^{1}$, José Carlos Ferreira Pinheiro Junior ${ }^{1}$, Tanny Thaylle de Souza ${ }^{1}$, Sibele Naiara Ferreira Germano ${ }^{1}$, Ana Paula Araújo Cavalcante ${ }^{2}$, Lourenny Regina Silva e Silva ${ }^{3}$.

\section{RESUMO}

Objetivo: Relatar uma experiência vivenciada durante o estágio acadêmico em um hospital de alta complexidade na cidade de Manaus, Amazonas. Relato de experiência: Tal relato baseia-se na história de vida de uma paciente idosa acometida por sequelas da hanseníase, que em decorrência da doença sofreu diversas formas de preconceito e segregação social. $O$ presente relato foi fundamentado em pesquisa de artigos científicos que abordam assuntos pertinentes à hanseníase (estigma, exclusão social, segregação) e protocolos do Ministério da Saúde referente à enfermidade. As técnicas para a coleta de dados foram: 1) análise do prontuário, em que foram extraídos a identificação da paciente, hipóteses diagnósticas, evolução médica diária; 2) anamnese da paciente; e 3) observação não estruturada. Através deste relato, observou-se que o estigma ainda é um fato real na sociedade, e a exclusão social ainda permeia a realidade da hanseníase. Considerações finais: Neste contexto, espera-se uma reflexão diante da complexidade que envolve a enfermidade, visto que vai além do esquema terapêutico, uma vez que o preconceito e a exclusão social continuam incrustados na sociedade, devido à falta de conhecimento em relação à doença.

Palavras-chave: Hanseníase, Estigma, Exclusão social.

\begin{abstract}
Objectives: To report an experience lived during the academic internship in a high complexity hospital in Manaus city, Amazonas state. Experience report: Such report is based on an elderly patient life history, who is affected by leprosy sequelae. As a result of her disease, she suffered from several ways of prejudice and social segregation. The present report was based on scientific articles that address relevant subjects to leprosy (stigma, social exclusion, segregation) and Health Ministry protocols regarding this disease. Data collection techniques were: 1) analysis of the medical record, from which the patient identification, diagnostic hypotheses, and daily medical evolution were extracted; 2) patient anamnesis; and 3) unstructured observation. Conclusion: Through out this report, it was observed that leprosy stigma is still a real fact in society, and social exclusion still permeates leprosy patients reality. In this context, it is expected to reflect on the complexity that surrounds this disease, since it goes beyond the therapeutic scheme. After all, prejudice and social exclusion are still embedded in society, due to missknowledge about the disease.
\end{abstract}

Keywords: Leprosy, Stigma, Social exclusion.

\section{RESUMEN}

Objetivo: Relatar una experiencia vivida durante el período académico en un hospital de alta complejidad en la ciudad de Manaus, Amazonas. Relato de experiencia: Este informe tiene base en la historia de vida de una paciente de edad avanzada afectada por secuelas de la enfermedad de Hansen, que como consecuencia sufrió diversas formas de prejuicio y segregación social. El presente informe tuvo base en la investigación de

\footnotetext{
1 Universidade Federal do Amazonas (UFAM), Coari-AM. *E-mail: reis.henrique.vasco@gmail.com

2 Universidade Pitágoras Unopar, Londrina-PR.

${ }^{3}$ Universidade do Norte (UNINORTE), Manaus-AM.
} 
artículos científicos que abordan cuestiones relacionadas con la enfermedad de Hansen (estigma, exclusión social, segregación) y protocolos del Ministerio de Salud relacionados con la enfermedad. Las técnicas de colecta de datos fueron; 1) Análisis del historial, en el que se extrajo la identificación de la paciente, hipótesis diagnósticas, evolución médica diaria; 2) anamnesis de la paciente; y 3) observación no estructurada. Conclusión: Por medio de este relato, se observó que el estigma aun es un hecho real en la sociedad, y la exclusión social aun impregna la realidad de la enfermedad de Hansen. En este contexto, se espera una reflexión sobre la complejidad que implica la enfermedad, ya que va más allá del esquema terapéutico, ya que los prejuicios y la exclusión social siguen incrustados en la sociedad, debido a la falta de conocimiento sobre la enfermedad.

Palabras clave: Hansen, Estigma, Exclusión social.

\section{INTRODUÇÃO}

A hanseníase é uma doença crônica, infectocontagiosa, cujo agente etiológico é o Mycobacterium leprae, que infecta principalmente os nervos periféricos. Sua transmissão ocorre pelas vias áreas superiores, devido ao convívio direto e prolongado com o doente que não iniciou tratamento específico. No entanto, a maioria dos indivíduos possuem imunidade contra o bacilo (BRASIL, 2017).

Quando diagnosticada, a notificação é compulsória através da ficha notificação/investigação do Sistema de Informação de Agravos de Notificação (SINAN) (BRASIL, 2016).

A organização Mundial da Saúde (OMS) recomenda para fins terapêuticos a classificação operacional baseada nos números de lesões cutâneas. Paucibacilares (PB), quando possuem até cinco lesões e Multibacilares (MB) com mais de cinco lesões. O diagnóstico consiste na epidemiologia, exame físico, laboratorial e baciloscópico do raspado intradérmico, que é um método frequentemente utilizado por ser de fácil execução, pouco invasivo e baixo custo (BRASIL, 2010; BRASIL, 2016).

O tratamento da hanseníase deve ser iniciado imediatamente após o diagnóstico, e é realizado por meio de medicamentos como Rifampicina, Dapsona e Clofazimina (poliquimioterapia - PQT) caso não haja contraindicações (BRASIL, 2017). Quando diagnosticado com hanseníase, o cliente vivencia um turbilhão de emoções e diante disto, os profissionais de saúde devem estar preparados para lidar com essas situações, tranquilizando e esclarecendo que a doença é curável (SILVEIRA MGB, et al., 2014).

A hanseníase pode afetar qualquer classe social, mas sua incidência é maior na população empobrecida, devido às condições precárias de vida e saúde, associadas ao baixo nível socioeconômico, que são um facilitador da propagação do bacilo, uma vez que a maior possibilidade de contágio ocorre em indivíduos desnutridos, residentes em ambientes fechados com pouco iluminação e ambiente insalubre (LOPES VAS e RANGEL EM, 2014).

Conhecida desde os tempos bíblicos a.C, a hanseníase já carregava consigo as marcas da exclusão social. No livro de Levítico, capítulo 13, versículos 2-45, são explicitadas as regras da Lei da Lepra, que determinavam que os sacerdotes deveriam fazer várias observações do estado da pele do doente e após essa avaliação, se entendessem que suas afecções se tratavam de lepra, o indivíduo era declarado impuro e deveria andar com as roupas rasgadas, despenteado, com a barba coberta e gritando: "Impuro! Impuro!".

O doente era considerado impuro enquanto durasse sua doença e deveria viver separado e morar fora do acampamento (BÍBLIA SAGRADA, 1993). As marcas deixadas no passado pelas ações profiláticas segregacionistas aos quais foram submetidos os portadores de hanseníase, assim como seus familiares, põem em dúvida as convicções quanto à sua terapêutica e a forma de infecção até a atualidade.

O estigma e o preconceito associados à hanseníase fazem parte da sociedade há vários anos, deixando consequências devastadoras na vida do indivíduo, principalmente para aqueles que, ainda que curados, apresentam sequelas físicas (RAMOS LBM, 2017).

Numa tentativa de diminuir o estigma da doença, o nome lepra foi substituído por hanseníase em 29 de março de 1995, com a Lei $n^{\circ} 9.010$. Art. $1^{\circ}$ : "O termo "Lepra" e seus derivados não poderão ser utilizados na linguagem empregada nos documentos oficiais da administração centralizada e descentralizada da União e dos Estados membros". 
O estigma é um atributo que desvaloriza a pessoa, gerando desigualdade social, reduzindo as oportunidades, impondo a perda da sua própria identidade, a pessoa passa a enxergar-se diferente do modelo que a sociedade impõe, com uma imagem deteriorada (HAMESTER CA, 2016), fragmentando a sua cidadania igualmente.

De acordo com Silva LF (2011), é preciso tratar a hanseníase e os doentes acometidos por essa patologia como qualquer outra doença. Acabando com o mito que o indivíduo doente recebeu castigo divino, visando reparar décadas de isolamento social.

Quando falamos do tratamento para hanseníase, o enfermeiro tem um papel de destaque, através da consulta de enfermagem é possível esclarecer quaisquer dúvidas sobre o tratamento, as complicações do abandono, as manifestações clínicas, além de estimular o autocuidado (RODRIGUES FF, et al., 2015). Neste contexto, por se tratar de uma doença bastante estigmatizada, o profissional deverá ter uma visão humanizada, uma vez que o indivíduo irá necessitar de maior apoio psicológico, emocional e físico (REGIS JC, et al., 2017).

Diante do exposto, o objetivo deste estudo é relatar a experiência vivenciada durante o estágio acadêmico em um hospital de alta complexidade na cidade de Manaus, Amazonas, onde observou-se que o estigma é um fato real na sociedade, e a exclusão social ainda permeia a realidade da hanseníase.

\section{RELATO DE EXPERIÊNCIA}

Trata-se de um relato de experiência do tipo descritivo, obtido durante acompanhamento assistencial no estágio curricular I, executado no setor da clínica médica, no período de 10 a 28 de setembro de 2018 , em um hospital situado em uma Cidade do Amazonas, sendo que, foi realizado por uma acadêmica do $9^{\circ}$ período do curso Bacharelado em Enfermagem, da Universidade Federal do Amazonas (UFAM).

O presente relato foi fundamentado em pesquisa de artigos científicos, que abordam assuntos pertinentes à hanseníase (estigma, exclusão social, segregação) e protocolos do Ministério da Saúde referente à enfermidade.

As técnicas para a coleta de dados foram: 1) análise do prontuário, em que foram extraídos a identificação da paciente, hipóteses diagnósticas, evolução médica diária; 2) anamnese da paciente; e 3) observação não estruturada.

No estágio curricular I, foi prestada assistência de enfermagem a uma idosa de 85 anos, cor branca, viúva, evangélica, aposentada, residente em um município do AM. A admissão da paciente no setor da clínica médica aconteceu no dia 11 de setembro de 2018, para investigação diagnóstica de Vasculopatia/Fenômeno de Lúcio. No momento da internação a cliente apresentava quadro álgico de gangrena de extremidades (quirodáctilos e pododáctilos).

A partir disso, foi eleita a referida paciente para amostragem, considerando a sua singular história de vida: diagnosticada com hanseníase virchowiana há 63 anos, sempre enfrentou preconceito, exclusão social e a falta de informação com relação à doença, carregando no corpo sequelas de anos sem tratamento.

Apresentando perda parcial da acuidade visual esquerda, madarose, surdez total em ouvido esquerdo e perda parcial da audição de ouvido direito, nariz em sela. Membro Superior Direito (MSD): apresenta mão em garra, ausência de sensibilidade tátil e dolorosa no antebraço e mão. No Membro Superior Esquerdo (MSE): mão em garra. Membro Inferir Direito (MID): hipotrofia da musculatura e perda da sensibilidade tátil dolorosa na perna. Membro Inferior Esquerdo (MIE): coto de amputação infrapatelar após úlcera infectada.

Paciente altamente dependente de cuidados para realização das atividades de vida diária. Até o término do presente estágio curricular I, que teve o encerramento dia 28 de setembro de 2018, a referida paciente ainda não apresentava diagnóstico definitivo.

No decorrer do estágio, pôde-se observar que a paciente sofreu ao longo da vida com inúmeras situações de enfrentamento do preconceito, estigma e exclusão social. Por meio de conversas com seus cuidadores, foi possível constatar que por muitos anos a paciente e seus familiares passaram por momentos difíceis em relação à doença. 
A paciente relatou para equipe médica que no início da doença, assim que teve sua primeira gestação, foi afastada de sua filha após o parto pela equipe hospitalar, devido a sua condição de saúde. Sua internação compulsória só não aconteceu porque na sua localidade não havia um leprosário. Este fato proporcionou grandes traumas psicológicos, pois foi rompido bruscamente o vínculo entre mãe e filha.

Quando sua filha completaria dois anos, a mãe recebeu a notícia que a criança veio a óbito, mas nunca houve uma explicação do diagnóstico que causou a morte. É importante ressaltar que a segregação entre mãe e filhos se fundamentava na Lei no 610 , de 13 de janeiro de 1949, que diz:

"Art. 15. Todo recém-nascido, filho de doente de lepra, será compulsória e imediatamente afastado da convivência dos pais"

"Art. 16. Os filhos de pais leprosos e todos os menores que convivam com leprosos serão assistidos em meio familiar adequado ou em preventórios especiais"

Morando em comunidade rural de um município do interior do Amazonas, a família era impedida de banharse, lavar louças e roupas no rio durante o dia, só realizavam suas atividades de vida diárias ao cair da noite, pois era a hora que a população se recolhia. Diante da gravidade do preconceito e exclusão social que era submetida diariamente e o medo de segregação da segunda filha, a família decidiu mudar-se do município Boca do Acre para Manaus, em uma embarcação própria, devido a medida profilática da época, que proibiam os leprosos de viajarem juntos com os indivíduos sadios.

Quando eram autorizados a viajarem, os indivíduos hansenianos deveriam ser colocados em canoas e puxados por uma corda amarrada à embarcação. Ao chegar a Manaus, a cliente acreditava que poderia passar despercebida, por se tratar de uma cidade grande e foi o que de fato ocorreu.

Outro ponto importante, que foi relatado pela paciente e sua filha no momento da anamnese está relacionado com a discriminação e o constrangimento sofrido por seu neto em ambiente escolar, pelo simples fato da presença de sua avó em uma reunião de pais.

A cliente relembra os olhares de repulsa dos pais e a perplexidade da professora. No entanto, o pior momento para a família foi quando seu neto relatou que seus colegas de classe não queriam sentar perto, nem interagir com ele.

A cliente não recorda o ano que recebeu tratamento para hanseníase, mas sabe que a terapêutica não conseguiu tratar o preconceito e reconhece que muitas coisas já mudaram para melhor na atualidade. Descreve também que a sociedade continua preconceituosa, mesmo que alguns casos de preconceitos sejam velados, além disto, relata que poderia passar dias falando sobre o estigma que sofre, mas apesar de tudo que passou ao longo da vida, nunca se deixou abater e foi na sua religião que sempre buscou forças para prosseguir.

\section{DISCUSSÃO}

Diante do exposto, observa-se que um dos maiores traumas da paciente referente à doença, está relacionado à quebra do vínculo materno com sua filha. Este fato coincide com as severas leis impostas no século XX, que determinava que:

"Os filhos de doente de lepra, logo após o nascimento, embora um só dos progenitores seja doente, serão separados e mantidos até à adolescência, quer em vigilância em domicilio, quer em preventórios especiais que, quando localizados na área do estabelecimento, ficarão anexos à zona de habitação das pessoas sãs, não podendo em caso algum ser nutridos no seio de uma ama, nem amamentados pela própria mãe, se esta estiver doente de lepra." (Decreto no $7558,11.11 .1938)$ "

A quebra cruel do vínculo familiar do paciente previsto em lei, submeteu esses seres humanos à brutal separação de seus filhos. Infelizmente em 1949 foi uma prática sanitarista comum para pais acometidos por hanseníase. Na época não se dava importância à manutenção dos laços familiares, não se respeitavam os direitos dos pais de participar da vida dos filhos, e obterem informações onde moravam e as suas condições de vida (ALMEIDA SSL, et al, 2012). 
Desta forma, as mães acometidas por hanseníase foram privadas de exercer o papel mais importante de suas vidas. Impossibilitadas de criar seus filhos, as mulheres revoltavam-se, e restava-lhes somente a incerteza do destino de seus recém-nascidos. Muitas receberam somente a notícia que seus filhos vieram a óbitos, no entanto, sem poderem enterrá-los, as mães acreditavam que suas crianças não faleceram, mas foram vendidas ou entregues para outras famílias (ALMEIDA SSL, et al, 2012).

Outro aspecto observado, é o preconceito que toda família de uma pessoa hanseniana pode enfrentar no contexto social. No caso da paciente, destacou-se o relato de seu neto, que sofreu exclusão social no ambiente escolar, evidenciando a necessidade de maior conhecimento acerca da doença.

Este fato corrobora com um estudo realizado em Cuiabá-MT, com estudantes de uma escola pública, constatando que, os alunos possuíam um falso entendimento da doença devido aos fortes traços culturais que predominam até os dias atuais na sociedade, encarando a hanseníase como doença perigosa, incurável, que necessita de reclusão social e que é motivo de constrangimento. Pode-se observar ainda, que muitas informações inverídicas que esses estudantes têm acesso, partem do próprio convívio familiar, pois muitos relatam que a família foi o único meio pelo qual se obteve conhecimento da doença. (FREITAS BHBM, et al, 2019)

Em um outro estudo realizado em 2016 com alunos de duas escolas de Goiânia - GO, identificou um baixo nível de conhecimento entre os jovens estudantes, além de demonstrar que a maioria dos alunos se mostraram preconceituosos em relação à hanseníase. Desta forma, o estudo destaca a importância da disseminação de informações no ambiente escolar uma vez que o preconceito contra os doentes de hanseníase será minimizado quando a sociedade conhecer a doença da forma correta, extinguindo o medo e os danos psíquicos. Essa educação deve-se iniciar nas escolas, onde os estudantes serão futuros formadores de opinião (ARRUDA JT, et al, 2016).

Diante do exposto, é notório que a paciente enfrentou diversas dificuldades em sua trajetória, que além de ser marcada por sequelas físicas da hanseníase, trouxe inúmeras consequências sociais e emocionais. No entanto, é possível verificar que embora o tratamento medicinal tenha sido de extrema importância na vida da paciente, ela buscou o amparo em sua crença espiritual como uma forma de superar e resistir às adversidades por qual passou.

Dessa forma, pode-se observar os efeitos significativos que as crenças podem exercer na saúde das pessoas, confirmando o conceito básico de saúde que vai além de fatores físicos (DAL-FARRA RA, 2019). Portanto, a religiosidade ou espiritualidade é uma ferramenta importante na vida do indivíduo que busca fortalecer sua saúde mental. Estima-se que $90 \%$ da população mundial estejam envolvidos em uma prática religiosa ou espiritual. Os templos religiosos ou igrejas são considerados abrigos sagrados para os fiéis, pois ajudam seus membros a lutarem contra as desigualdades da sociedade (REINALDO AMS, SANTOS RLF, 2016; RIBEIRO FML, MINAYO MCS, 2013).

De modo geral, a espiritualidade pode influenciar o paciente no enfrentamento da dor, adesão ao tratamento, diminuição de ansiedade e estresse, pois proporciona ao doente o conforto emocional diante de seus anseios e preocupações relacionados à doença, uma vez que passam a transferir todas as suas ansiedades para a divindade superior na qual acreditam (LEMOS CT, 2019).

\section{CONSIDERAÇÕES FINAIS}

É preciso um olhar crítico e reflexivo diante da complexidade que envolve a hanseníase, visto que o tratamento vai além de um esquema terapêutico. É importante destacar que o preconceito e a exclusão social continuam incrustados na sociedade, devido à falta de conhecimento em relação à doença. As deformidades tornam o doente prisioneiro do seu próprio corpo, do seu lar, a descoberta do bacilo de Hansen e a cura não foram suficientes para mudar a maneira de entender a doença e as representações sociais na modernidade. Para o acadêmico de enfermagem, essa abordagem torna-se importante para capacitá-lo a enxergar a hanseníase além de suas sequelas físicas. Desta forma, o futuro profissional estará apto a atuar na assistência do indivíduo considerando-o em todas as suas particularidades. Neste contexto, cabe ao enfermeiro realizar um cuidado integral aos pacientes, familiares e desenvolver junto à comunidade ações a fim de minimizar o estigma social. 


\section{REFERÊNCIAS}

1. ALMEIDA SSL, et al. Maternidade e hanseníase: as vivências de separação devido ao isolamento compulsório. Revista Estudos de Psicologia, 2012; 275-281.

2. ARRUDA JT, et al. Hanseníase e o preconceito: estudo de caso em escola da rede de educação básica de GoiâniaGO, Brasil. Revista Eletrônica de Educação da Faculdade Araguaia, 2016; 9:123-135.

3. BÍBLIA. Levítico. Bíblia Sagrada. Traduzida em português por João Ferreira de Almeida. Revista e atualizada no Brasil. 2 ${ }^{a}$ Edição. Editora São Paulo: Sociedade Bíblica do Brasil, 1993; 107-108p.

4. BRASIL. Lei n ${ }^{\circ} 9.010$, de 29 de março de 1995. Dispõe sobre a terminologia oficial relativa à hanseníase e dá outras providências. Diário oficial da união, Brasília, D,30 de março de 1995; secão 1.p.4509.

5. BRASIL. Lei $n^{\circ} 610$, de 13 de janeiro de 1949. Fixa normas para a profilaxia da lepra.

6. DAL-FARRA RA, Geremia C. Educação em saúde e espiritualidade: proposições metodológicas. Rev Bras Educ Med. 2010; 34(4):587-97.

7. FREITAS BHBM, et al. Percepção de adolescentes sobre hanseníase. Revista de enfermagem UFPE online, 2019; 13(2): 292-7.

8. HAMESTER CA. Hanseníase na experiência de vida de pessoas atendidas em ambulatório de referência no Distrito Federal. Dissertação (Mestrado em Saúde Coletiva) - Universidade de Brasília, 2016; 24p.

9. LEMOS CT. Espiritualidade, religiosidade e saúde: uma análise literária. Revista Caminhos, 2019; 2(17): 688-708.

10. LOPES VAS, RANGEL EM. Hanseníase e vulnerabilidade social: uma análise do perfil socioeconômico de usuários em tratamento irregular. Revista Saúde Debate, 2014; 103(38): 817-829.

11. Mateus. Bíblia Sagrada. Traduzida em português por João Ferreira de Almeida. Revista e atualizada no Brasil. $2^{\underline{a}}$ Edição. Editora São Paulo: Sociedade Bíblica do Brasil, 1993; 869p.

12. Ministério da Saúde. Secretaria de Vigilância em Saúde. Departamento de Vigilância das Doenças Transmissíveis. Guia prático sobre a hanseníase/ Ministério da Saúde, Secretaria de Vigilância em Saúde, Departamento de Vigilância das Doenças Transmissíveis. - Brasília: Ministério da Saúde, 2017.

13. Ministério da Saúde. Secretaria de Vigilância em Saúde. Departamento de Vigilância das Doenças Transmissíveis. Diretrizes para vigilância, atenção e eliminação da Hanseníase como problema de saúde pública: manual técnicooperacional/Ministério da Saúde, Secretaria de Vigilância em Saúde, Departamento de Vigilância das Doenças Transmissíveis. - Brasília: Ministério da Saúde, 2016.

14. Ministério da Saúde. Secretaria de Vigilância em Saúde. Departamento de Vigilância Epidemiológica. Guia de procedimentos técnicos: baciloscopia em hanseníase / Ministério da Saúde, Secretaria de Vigilância em Saúde, Departamento de Vigilância Epidemiológica. - Brasília: Editora do Ministério da Saúde, 2010.

15. RAMOS LBM. Hanseníase e estigma no século XXI: narrativas de moradores de um território endêmico. Tese (Doutorado em Ciências da Saúde) - Universidade Federal de Uberlândia, Uberlândia, 2017; 101p.

16. REGIS JC, et al. A atuação do enfermeiro na consulta de enfermagem ao paciente com hanseníase: um estudo de revisão, 2017.

17. REINALDO AMS, SANTOS RLF. Religião e transtornos mentais na perspectiva de profissionais de saúde, pacientes psiquiátricos e seus familiares. Revista Saúde Debate, 2016; 110 (40): 162-171.

18. RIBEIRO FML, MINAYO MCS. O papel da religião na promoção da saúde, na prevenção da violência e na reabilitação de pessoas envolvidas com a criminalidade: revisão de literatura. 2013.

19. RODRIGUES FF, et al. Conhecimento e prática dos enfermeiros sobre hanseníase: ações de controle e eliminação. Revista Brasileira de Enfermagem, 2015; 298-302.

20. SILVA LF, História da lepra ou hanseníase? O problema da terminologia na história da doença. Anais do XXVI Simpósio Nacional de História. São Paulo, 2011.

21. SILVEIRA MGB, et al. Portador de hanseníase: impacto psicológico do diagnóstico. Revista Psicologia \& Sociedade, $2014 ; 2(26): 517-527$. 